\title{
Analisis Perilaku Masyarakat Dalam Membuang Sampah Di Btn. Baiti Jannati Sumbawa
}

\author{
Sumitro \\ Prodi Sosiologi Institut Ilmu Sosial dan Ilmu Budaya Samawa Rea \\ Email: sumitro765@gmail.com
}

\begin{abstract}
Abstrak. Sampah merupakan sesuatu yang tidak dapat dijauhkan dari kehidupan manusia sehari hari. Secara umum bagi manusia sampah dapat berdampak buruk pada kehidupan dan kesehatan manusia jika tidak dapat digunakan dan dikelola dengan benar. Terlebih lagi ketika sampah dibuang sembarangan atau ditumpuk tanpa ada pengelolaan yang baik, maka akan menimbulkan berbagai dampak kesehatan yang serius. Beberapa penyakit dapat ditimbulkan karena binatang yang hidup dalam tumpukan sampah. Lalat merupakan binatang yang suka hidup di tempat-tempat kotor, seperti tumpukan sampah dapat menjadi penyebab penyakit diare. Dengan demikian maka yang menjadi rumusan masalah dalam penelitian ini adalah bagaimana perilaku masyarakat dalam membuang sampah di BTN. Baiti Jannati Sumbawa. Metode penelitian yang digunakan adalah kualitatif dengan pendekatan deskriptif kualitatif. Teknik pengumpulan data dalam penelitian ini adalah observasi, wawancara dan dokumentasi. Adapun hasil penelitian ini menunjukkan bahwa; pertama masih ada masyarakat yang membuang sampah di sepanjang jalan masuk btn.baiti jannati. Kedua masih adanya masyarakat yang menyimpan sampah di luar pagar rumah sebelum hari penjemputan oleh petugas kebersihan.
\end{abstract}

Kata kunci : Analisis, Perilaku Masyarakat,Sampah.

Abstract. Abstract. Garbage is something that cannot be kept away from everyday human life. In general, for humans, waste can have a negative impact on human life and health if it is not used and managed properly. Moreover, when garbage is dumped carelessly or piled up without proper management, it will cause serious health impacts. Some diseases can be caused by animals living in garbage heaps. Flies are animals that like to live in dirty places, such as garbage piles that can cause diarrhea. Thus, the problem formulation in this study is how the community's behavior in disposing of waste at BTN. Baiti Jannati Sumbawa. The research method used is qualitative with a qualitative descriptive approach. Data collection techniques in this study were observation, interviews and documentation. The results of this study indicate that; first, there are people who throw garbage along the entrance to btn.baiti jannati. Second, there are still people who store garbage outside the house fence before the day of pick-up by cleaning personnel.

Keywords: Analysis, Community Behavior, Garbage

\section{PENDAHULUAN}

\section{Latar Belakang Masalah}

Sampah merupakan sesuatu yang tidak dapat dijauhkan dari kehidupan manusia sehari hari. Secara umum bagi manusia sampah dapat berdampak buruk pada pada kehidupan dan kesehatan manusia jika tidak dapat digunakan dan dikelola dengan benar. Terlebih lagi ketika sampah dibuang sembarangan atau ditumpuk tanpa ada pengelolaan yang baik, maka akan menimbulkan berbagai dampak kesehatan yang serius. Beberapa penyakit dapat ditimbulkan karena binatang yang hidup dalam tumpukan sampah. Lalat merupakan binatang yang suka hidup ditempat - tempat kotor, seperti tumpukan sampah dapat menjadi penyebab penyakit diare. Lalat yang hidup ditempat yang kotor membawa kuman bakteri penyebab diare. Tikus dapat membawa bibit penyakit pes, leptospirosis dan salmonellosis. Sedangkan serangga (lalat, kecoa, lipas, kutu) dapat membawa berbagai bakteri yang menyebabkan penyakit disentri dan diare. 
Jurnal Ilmu Sosial dan Pendidikan

http://ejournal.mandalanursa.org/index.php/JISIP/index

Terakreditasi Peringkat 5 (No. SK: 85/M/KPT/2020)

Sampah yang semula indentik dengan dampak negatif yang ditimbulkannya, perlu dicarikan jalan keluar atau ada inovasi yang merubah dari yang bersifat negatif menjadi bersifat positif. Salah satu upaya yang dilakukan oleh Kementerian Lingkungan Hidup Kabupaten sumbawa untuk menangani sampah dengan menaruh kontainer sampah. Program yang dicanangkan oleh Kementrian Lingkungan Hidup ini selain bertujuan untuk menjaga kelestarian lingkungan hidup, bertujuan juga untuk membangun kesadaran masyarakat agar lebih peduli terhadap permasalahan sampah di sekitar mereka.

Permasalahan sampah di BTN Baiti Jannati menjadi perhatian serius bagi pemangku jabatan dan masyarakat yang peduli akan kebersihan lingkungan. Terlebih dengan adanya adanya sebagian anggota masyarakat yang menaruh dan membuang sampah di sepanjang jalan masuk Kompleks BTN. Baiti JannatiSumbawa. Sehingga peneliti tertarik untuk melakukan penelitian ini dengan harapan ditemukan formulasi yang tepat untuk penanganan masalah dampak negatif akibat dari kurangnya kesadaran masyarakat dalam membuang sampah baik di jalan stapak di setiap blok maupun di sepanjang jalan utama BTN. Baiti Jannati Sumbawa. Dengan demikian peneliti tertarik untuk melakukan penelitian dengan judul " Analisis Perilaku Masyarakat yang Membuang Sampah di BTN Baiti Jannati Sumbawa.

\section{Rumusan Masalah}

Berdasarkan hal-hal yang telah dikemukakan di atas, maka dapat dirumuskan permasalahan pokok dalam penelitian ini sebagai berikut : Bagaimana perilaku masyarakat dalam membuang sampah di BTN. Baiti Jannati Sumbawa?

\section{METODE PENELITIAN \\ Pendekatan Penelitian}

Jenis penelitian yang digunakan dalam penelitian ini adalah penelitian deskriptif kualitatif. Menurut Bogdan dan Taylor, metodologi kualitatif adalah prosedur penelitian
Vol. 4. No. 4 November 2020

p-ISSN: 2598-9944 e- ISSN: 2656-6753

yang menghasilkan data deskriptif berupa katakata tertulis dari orang-orang dan perilaku yang dapat diamati (Moleong, 2002:3).

Deskriptif kualitatif yaitu dengan mendeskripsikan kualitas suatu gejala yang menggunakan ukuran perasaan sebagai dasar penilaian, penelitian deskriptif bermaksud untuk memberikan uraian mengenai suatu gejala sosial yang diteliti. Peneliti mendeskripsikan suatu gejala berdasarkan pada indikator-indikator yang dia jadikan dasar dari ada tidaknya suatu gejala yang dia teliti (Slamet, 2006:7).

Metode kualitatif dapat digunakan untuk mempelajari, membuka dan mengerti apa yang terjadi di belakang setiap fenomena yang baru sedikit diketahui. Oleh karena itu metode penelitian yang digunakan dalam penelitian ini adalah metode penelitian kualitatif. Penelitian ini menggambarkan perilaku masyarakat dalam membuang sampah di BTN. Baiti Jannati Sumbawa.

\section{Lokasi dan Subyek Penelitian}

Penelitian ini dilakukan pada masyarakat BTN.Baiti Jannati Sumbawa. Masyarakat yang diteliti terdiri dari Pemerintah setempat, petugas pengangkut sampah, tokoh masyarakat maupun masyarakat sebagai penduduk BTN.Baiti Jannati Sumbawa. Lokasi penelitian berada di kompleks BTN.Baiti Jannati Sumbawa .

\section{Fokus Penelitian}

Menurut Moleong (2004:237) tidak ada satupun penelitian yang dapat dilakukan tanpa adanya fokus yang diteliti. Adanya fokus penelitian membatasi studi yang berarti bahwa dengan adanya fokus yang diteliti akan memunculkan suatu perubahan atau obyek penelitian menjadi lebih terpusat atau terarah. Kemudian penentuan fokus penelitian akan dapat menetapkan kriteria-kriteria untuk menjaring informasi yang diperoleh.

Penetapan fokus penelitian ini merupakan tahap yang sangat menentukan dalam penelitian kualitatif. Hal tersebut karena suatu penelitian kualitatif tidak dimulai dari sesuatu yang kosong atau tanpa adanya masalah, baik masalah-masalah yang bersumber dari 
Jurnal Ilmu Sosial dan Pendidikan

http://ejournal.mandalanursa.org/index.php/JISIP/index

Terakreditasi Peringkat 5 (No. SK: 85/M/KPT/2020)

pengalaman penelitian atau melalui pengetahuan yang diperolehnya melalui kepustakaan ilmiah. Jadi fokus dalam penelitian kualitatif sebenarnya merupakan masalah itu sendiri (Moleong, 2002:62). Berpedoman pada konsep tersebut maka yang menjadi fokus dalam penelitian ini adalah:

1. Perilaku masyarakat dalam membuang sampah di BTN. Baiti Jannati Sumbawa.

\section{Sumber Data}

Sumber data yang digunakan peneliti dalam penelitian ini dibedakan menjadi:

1. Sumber data primer

Sumber data utama atau primer adalah kata-kata dan tindakan orang-orang yang diamati atau diwawancarai (Moleong, 2002:112). Pencacatan sumber data utama melalui pengamatan atau observasi dan wawancara merupakan hasil usaha gabungan dari kegiatan melihat, mendengar dan bertanya yang dilakukan secara sadar, terarah, dan senantiasa bertujuan memperoleh informasi yang diperlukan. Informan yaitu orang dalam latar penelitian yang dimanfaatkan untuk memberikan informasi tentang situasi dan kondisi latar penelitian (Moleong, 2002:90). Informan dalam penelitian ini adalah 6 orang masyarakat BTN Baiti Jannati Sumbawa.

\section{Sumber data sekunder}

Selain kata-kata dan tindakan sebagai sumber data utama, diperlukan juga data tambahan seperti dokumen dan lain-lain sebagai sumber data sekunder (Moleong, 2002:113). Jadi sumber data sekunder merupakan sumber data yang diperoleh tidak langsung yang berguna untuk mendukung data primer. Sumber data ini berupa data-data statistik kependudukan di kecamatan Hilir

\section{Teknik Pengumpulan Data}

Wawancara mendalam adalah teknik pengumpulan data dimana peneliti mengajukan pertanyaan-pertanyaan tentang segala sesuatu kepada informan untuk memperoleh informasi yang diharapkan. Teknik wawancara ini tidak dilakukan dengan menggunakan struktur yang ketat atau semi formal agar keterangan yang diperoleh dari informan memiliki kedalaman dan keleluasaan, sehingga mampu memperoleh
Vol. 4. No. 4 November 2020

p-ISSN: 2598-9944 e- ISSN: 2656-6753

informasi yang sebenarnya.

Validitas Data

Dalam penelitian ini menggunakan teknik triangulasi dalam mencapai validitas data. Teknik triangulasi adalah teknik penarikan keabsahan data dengan memanfaatkan penggunaan sesuatu yang lain di luar data itu untuk keperluan penyelesaian atau sebagai pembanding terhadap data yang sudah ada. Dimana dalam penelitian ini menggunakan triangulasi sumber. Artinya membandingkan dan mengecek kembali derajat kepercayaan suatu sumber informasi yang diperoleh melalui waktu dan alat yang berbeda dalam metode kualitatif.

\section{Teknik Analisis Data}

Sesuai dengan teknik pengumpulan data tersebut maka analisanya berkembang dan berjalan serta berlangsung proses di saat pengumpulan data dilakukan. Peneliti bekerja dengan data atau dengan teknik analisa data interactive of analysis yang mempunyai tahaptahap sebagai berikut :

1. Pengumpulan Data (Data Collection)

Pengumpulan data dilakukan dengan mewawancarai informan kemudian mendokumentasikannya. Pengumpulan data ini dilakukan selama data yang diperlukan kurang memenuhi kebutuhan dan akan dihentikan jika data yang diperlukan sudah memenuhi kebutuhan, serta bisa ditarik kesimpulan.

2. Reduksi Data (Data Reduction)

Dalam proses seleksi, pemfokusan, penyederhanaan, pengabstrakan dan transformasi data kasar yang muncul dari catatan-catatan tertulis di lapangan. Proses ini berlangsung terus sepanjang penelitian dimulai.

3. Penyajian Data (Data Display)

Dalam penyajian data disusun dengan baik dan jelas supaya peneliti mudah mendapatkan gambaran yang jelas tentang data keseluruhan guna menyusun kesimpulan.

4. Penarikan Kesimpulan (Conclusions)

Dari permulaan pengumpulan data, peneliti mengerti arti dari hal-hal temuan di 
Jurnal Ilmu Sosial dan Pendidikan

http://ejournal.mandalanursa.org/index.php/JISIP/index

Terakreditasi Peringkat 5 (No. SK: 85/M/KPT/2020)

lapangan dengan mencatat pola-pola pernyataan yang mungkin karena sebab akibat. Dari teknik analisa Data Interactive Model Of Analysis di atas dapat digambarkan dalam sebuah bagan seperti dibawah ini :

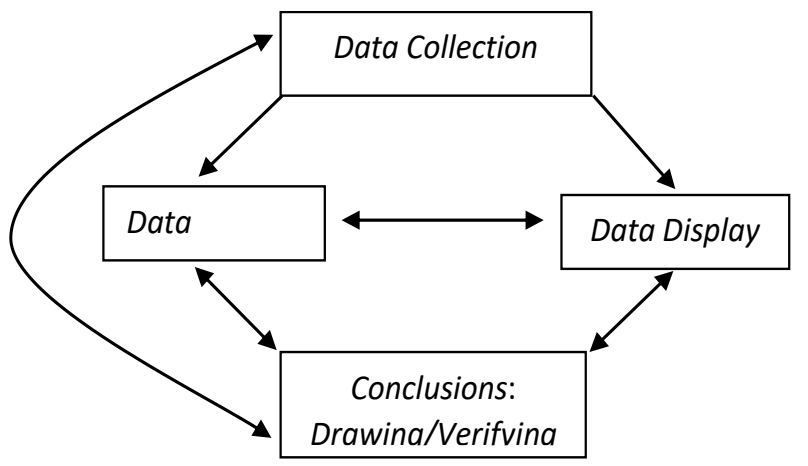

Bagan 2. Komponen dalam Analis Data (Interactive Model) Sumber: (Sugiono, 2011:247)

\section{HASIL PENELITIAN DAN PEMBAHASAN}

Perilaku masyarakat dalam membuang sampah di BTN. Baiti Jannati Sumbawa.

1. Masih adanya masyarakat yang membuang sampah di sepanjang jalan masuk btn.baiti jannati.

Dalam penelitian ini menemukan bahwa Perilaku masyarakat yang membuang sampah pada kawasan perumahan baiti jannati sumbawa dapat dijabarkan sebagai berikut; pertama, Aspek perilaku masyarakat. Perumahan baiti jannati merupakan perumahan yang baru berdiri pada tahun 2016, dengan keberadaan perumahan baru ini tentu berbagai macam kekurangan dan keterbatasan dalam hal fasilitas yang tersedia. Seperti halnya dengan ketersediaan fasilitas tempat pembuangan sampah, sehingga masyarakat bingung dalam membuang sampah, hal ini juga diperparah oleh perilaku masyarakat yang kurang peduli terhadap kebersihan lingkungannya. Senada dengan pendapat ketua RW bahwa masih ada masyarakat yang apatis dengan kebersihan lingkungan baiti jannati, padahal pemerintah setempat sudah menyediakan fasilitas pengangkut sampah dengan hari penjemputan sampah 2 kali seminggu, namun masih ada
Vol. 4. No. 4 November 2020

p-ISSN: 2598-9944 e- ISSN: 2656-6753

masyarakat yang membuang sampah di sepanjang jalan masuk BTN.Baiti jannati. Padahal mayoritas penduduk yang ada di perumahan tersebut adalah rata-rata berpendidikan dan bekerja di sektor formal. Dengan melihat kondisi demikian ketua RW bersama tokoh masyarakat melakukan gotong royong setiap hari minggu untuk membersihkan sampah yang ada di sepanjang jalan masuk perumahan, namun hal yang terualang tetap saja ada sebagian masyarakat dengan sengaja membuang sampah disepanjang jalan masuk, anehnya lagi sampai sekarang tidak ada yang mengetahui siapa pelaku yang membuang sampah tersebut. Berdasarkan informasi dari informan yang peneliti wawancara bahwa pembuangan sampah di jalan masuk perumahan tersebut dilakukan pada malam hari,sehingga susah untuk mengetahui siapa pelakunya. Adapun usaha preventif yang dilakukan oleh pihak pemerintah setempat dengan cara menyewah pihak ke tiga sebagai jasa pengangkutan sampah secara langsung ke rumah-rumah warga, dengan harapan tidak ada lagi masyarakat yang membuang sampah sembarangan dilingkungan perumahan baiti jannati sumbawa. Namun berdasarkan hasil wawancara dengan tokoh masyarakat, masih ada juga anggota masyarakat yang tidak tertib dalam membuang sampah, menurut informan bahwa masyarakat yang membuang sampah di jalan masuk adalah benar-benar masyarakat yang tidak bermoral karena sudah berbagai cara dilakukan oleh pemerintah dan tokoh masyarakat untuk terus menyosialisasikan hidup bersih dan peduli lingkungan namun tetap saja ada sebagian anggota masyarakat yang tidak patuh terhadap penyuluhan yang dilakukan. Kedua; aspek kesadaran sosial. Dalam kehidupan sosial kemasyarakatan, kesadaran sosial sangat diperlukan terlebih lagi dalam kehidupan di perumahan baiti jannati yang anggota masyarakatnya yang sangat heterogen. Berkaitan dengan sampah yang ada di baiti jannati sumbawa. Berdasarkan pengamatan dan hasil wawancara Peneliti dengan informan bahwa masih kurangnya kesadaran anggota masyarakat dalam membuang sampah, sehingga 
Jurnal Ilmu Sosial dan Pendidikan

http://ejournal.mandalanursa.org/index.php/JISIP/index

Terakreditasi Peringkat 5 (No. SK: 85/M/KPT/2020)

tidak jarang kita temukan sampah berserahkan di sepanjang jalan masuk perumahan baiti jannati. Untuk bisa menertibkan sampah dibaiti jannati selain kesadaran yang tinggi juga dibutuhkan nilai solidaritas sebagai rasa kebersamaan, rasa kesatuan kepentingan, rasa simpati, sebagai salah satu kesatuan anggota dari kelas yang sama.(Sumitro, 2020).

2. Masih ada masyarakat yang menyimpan sampah di luar pagar rumah sebelum hari penjemputan oleh petugas kebersihan.

Khusus di lingkungan BTN Baiti Jannati Pemerintah kabupaten Sumbawa lewat dinas Dinas Kebersihan, pertamanan dan PMK mengusahakan layanan kebersihan dengan mengirim petugas kebersihan tiap 2 kali seminggu. Pengambilan sampah dilingkungan ini di jadwalkan tiap hari kamis dan hari minggu. Proses pengambilan sampah dilakukan dengan mengirim truk sampah dengan tiga orang petugas kebersihan untuk mengangkut sampah warga masyarakat.

Tenaga kebersihan di kabupaten Sumbawa secara umum masih minim, karena tenaga kerja yang ada saat ini sebanyak 136 orang. Untuk menangani sampah secara total diperkirakan dibutuhkan sekitar 535 tenaga kerja. Karena satu orang tenaga kerja dapat menangani 1.000 meter kubik sampah. Dengan adanya keterbatasan ini tentunya dibutuhkan peran aktif masyarakat dalam menjaga kebersihan di lingkungannya masing masing. (nusramedia.com, 2019)

Salah satu cara untuk berpartisipasi dalam menjaga kebersihan tersebut adalah dengan menyimpan sampah di luar pagar rumah pada hari penjemputan oleh petugas kebersihan. Hal ini mungkin terkesan sederhana, namun hal itu cukup membantu petugas, sehingga waktu yang diperlukan untuk mengumpulkan sampah menjadi lebih efektif, mengingat keterbatasan jumlah petugas.

Terkait usaha membantu petugas kebersihan dilingkungan masing-masing ini diharapkan ketepatan dalam tindakan masyarakat. Tidak tepatnya tindakan warga dalam usaha bersama menjaga kebersihan
Vol. 4. No. 4 November 2020

p-ISSN: 2598-9944 e- ISSN: 2656-6753

lingkungan dapat menimbulkan masalah lain terkait kebersihan lingkungan. Di satu sisi terlalu cepat menyimpan sampah didepan rumah membuat lingkungan menjadi kotor dan berbau. Dan di sisi lain ketika tidak rutin menyimpan sampah di depan rumah membuat sampah menumpuk dan membuat petugas kewalahan mengangkut sampah. Ketika warga terlalu cepat menyimpan sampah di depan rumah membuat lingkungan menjadi kotor dan berbau. Hal ini diperparah dengan adanya anjing liar yang dan kucing liar yang mengorek-orek sampah, sehingga sampah berceceran ke jalan sehingga menimbulkan bau yang tidak sedap. Tidak jarang pula sampah itu jatuh ke selokan dan menyumbat aliran air. Ketika musim hujan tiba masalah lain muncul, dimana pembusukan sampah menjadi lebih cepat sehingga menimbulkan berbagai macam penyakit.

Ketika warga tidak rutin menyimpan sampah di depan rumah membuat sampah menumpuk dan membuat petugas kewalahan mengangkut sampah. Jumlah petugas kebersihan yang terbatas membuat warga membutuhkan tenaga tambahan untuk membantu mengangkut sampah di lingkungan baiti Jannati. Sangat disayangkan ketika warga telah membaya $\mathrm{r}$ iuran sebesar Rp. 15.000,tetapi warga sendiri tidak memanfaatkan dengan baik layanan kebersihan yang didapatkan. Selain perilaku menumpuk sampah dalam rumah dapat juga menimbulkan berbagai macam penyakit.

\section{DAFTAR PUSTAKA}

Berger, P.L \& Luckmann, T. 1990. Tafsir Sosial Atas Kenyataan: Sebuah Risalah tentang Sosiologi

Pengetahuan. (Terjemahan: Hasan Basari). Jakarta: LP3ES

Demartoto, Argyo. 2013. Teori Konstruksi Sosial dari Peter L. Berger dan Thomas Luckmann. (http://argyo.staff.uns.ac.id).

Diakses: 3 Januari 2015.

Meleong, Lexy. 2002. Metode Penelitian Kualitatif . Bandung: Remaja Rosda Karya.

Mulyanti, K., \& Fachrurrozi, A. (2017). ANALISIS 
Terakreditasi Peringkat 5 (No. SK: 85/M/KPT/2020) 